\title{
Determination of Carbon Steel Dynamic Properties
}

Miroslav Jopek (ORCID: 0000-0001-5399-3059)

Faculty of Mechanical Engineering, Brno University of Technology, Technická 2, 61669 Brno, Czech Republic. E-mail: jopek@fme.vutbr.cz

Taylor anvil test is one of the dynamic test method in which we can determine the dependences of strain, strain rate, temperature on flow stress. With this method, we can determine in each cross section or along axial section of the test specimen conditions under different states of stress, strain, strain rates and subsequent changes in the microstructure of the material. This paper describes the experimental results of the Taylor anvil test (TAT) for TRISTAL carbon steel. The experiment was performed on a TAT test facility in the Laboratory of High Strain Rates at the Faculty of Mechanical Engineering in Brno.

For simulation of the mechanical behavior of TRISTAL steel under dynamic load condition was used LS DYNA 3D. This paper also contains the results of the Johnson-Cook constitutive equation for TRISTAL steel. The simulation results are compared with the experimental TAT results.

Keywords: Taylor anvil test, FEM, high strain rate, dynamic load

\section{Introduction}

Most of the forming processes are proceed in dynamic strain conditions. During these processes the blanks and forming tools used are subject to impact stressing. In practice, the blanks are processed on automatic forming machines; they are formed at strain rates ranging between $\varphi^{*}=1-10^{3} \mathrm{~s}^{-1}$ (so called medium rate), e.g. in the production of connecting parts and machine parts. This is why a description of the forming behaviour at high strain rates is important. The Taylor anvil test (TAT) is example of the experimental methods used for the investigation of mechanical properties at high strain rates. $[1,2]$

One of the basic mechanical characteristics of materials is the dependence between stress and strain. This dependence is important for determining the beginning of plastic deformation, i. e. the yield stress, and it is particularly necessary for mathematical simulations of forming processes, and also for many common technological calculations and dimensioning of forming tools in simulation programs (e.g. DEFORM, SIMUFACT, etc.). [3, 4]. Today material models are mainly based on the quasi-static values of mechanical properties of materials (approximately to $\varphi^{*} \leq 1 \mathrm{~s}^{-1}$ ), so-called strain hardening curves (stress-strain curves) [5]. These dependence relations do not take into consideration the dynamic behaviour of the material in conditions of actual forming operation (temperature, strain rate). This is why it is necessary to obtain the stress-strain curves of the formed materials in real forming conditions.

\section{Procedure of experiment evaluation}

The experiments were carried out by means of the Taylor Anvil Test (TAT). By its conception the TAT approximates real loading, be it by the possible changes in the tested specimens or by its simple geometry. The principle of the TAT consists in impacting a cylindrical specimen against a rigid wall at a variable impact rate. Fig. 1 shows the cylindrical specimen before loading and in the Fig. 2 is specimen after loading.

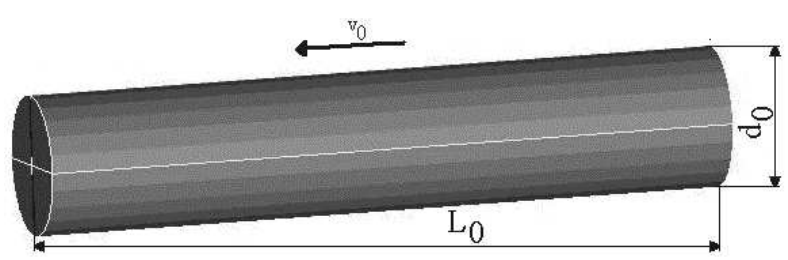

Fig. 1 Specimen before loading.

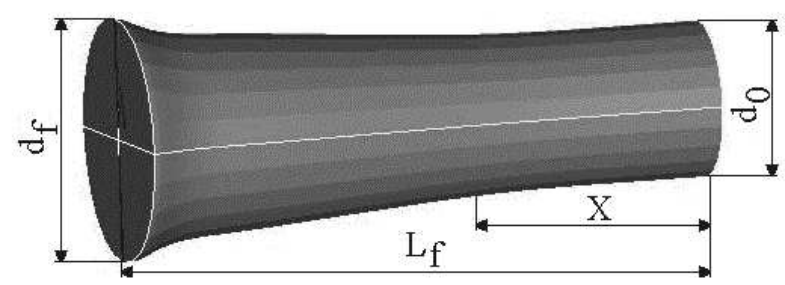

Fig.2 Specimen after loading

Tab. 1 Chemical composition of TRISTAL steel

\begin{tabular}{|l|c|c|c|c|c|c|c|c|c|}
\hline Designation & $\mathrm{C} \%$ & $\mathrm{Mn} \%$ & $\mathrm{Si} \%$ & $\mathrm{P} \%$ & $\mathrm{~S} \%$ & $\mathrm{Cr} \%$ & $\mathrm{Ni} \%$ & $\mathrm{~W} \%$ & $\mathrm{Cu} \%$ \\
\hline TRISTAL & 0.1 & 0.38 & 0.07 & 0.012 & 0.008 & 0.05 & 0.04 & 0.01 & 0.1 \\
\hline
\end{tabular}


The specimens were made of BCC steels, i. e. TRISTAL. Chemical composition of this steel is shown in Tab 1.

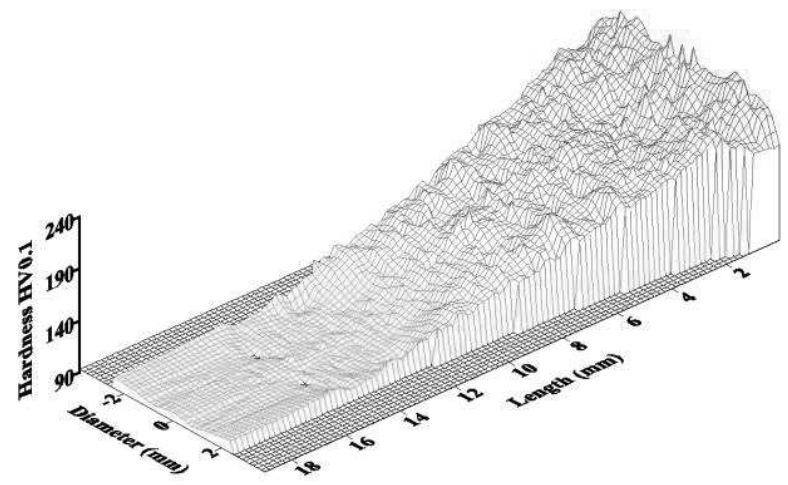

Fig. 3 Specimen hardness (along axial section) of the TRISTAL steel after loading at an impact rate of 235, 8

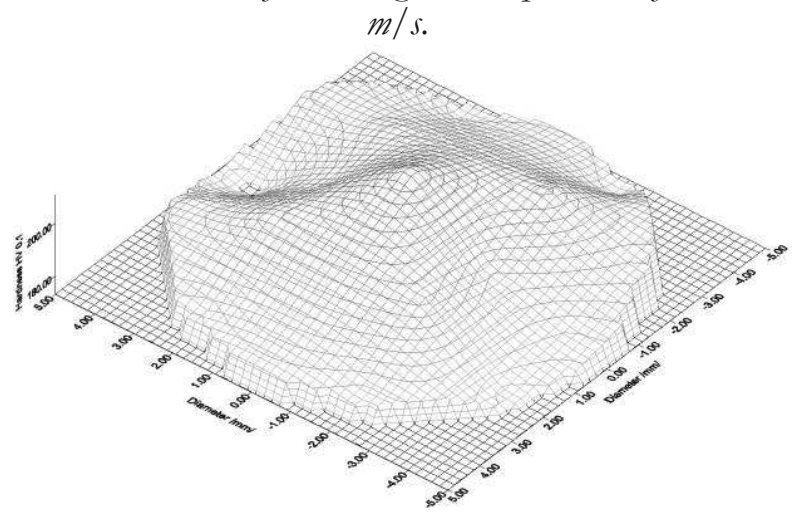

Fig. 4 Specimen hardness (impact forehead) of the TRISTAL steel after loading at an impact rate of 235,8 $\mathrm{m} / \mathrm{s}$.

To complete analysing the resultant data is necessary describe a change hardness in the longitudinal section of the specimen in dependence on the projectile impact rate. Fig. 3 shows that hardness increases towards the surface of the impact area. Initial hardness of the specimen before loading was $95 \mathrm{HV}$, while after loading its maximum was $200 \mathrm{HV}$. Fig. 4 shows, that hardness decrease to outskirts specimen.

To geometrical analysis the contour specimens was use the CCD camera and software LUCIA. This geometrical analysis is necessary to compare experimental and simulated results.

This information serves as input data for the analysis of mechanical characteristics, e.g. the dependence between stress and strain. Boundary factors such as friction, temperature, etc., are of essential importance for a precise analysis of the experiment. Determination of a mathematical model of general validity, which describes the deformation behaviour of the formed steel at real load rates, is quite difficult because inertial forces and mechanical resonance also come into play.

Constitutive equation, which are usually empirical and comprehend the basic physical parameters and the dependence on strain rate, temperature and strain, seam to be suitable. One of the most often used mathematical models is the Johnson and Cook constitutive equation (1) $[6,7]$, in which flow stress is a function of strain, strain rate and temperature.

$$
\sigma=\left(A+B \phi^{n}\right)\left(1+C \ln \frac{\dot{\phi}}{\dot{\phi}_{0}}\right)\left(1-\left(\frac{T-T_{0}}{T_{m}-T_{0}}\right)^{m}\right),
$$

Where:

$\mathrm{A}, \mathrm{B}, \mathrm{C}, \mathrm{n}, \mathrm{m}$... Material constants determined experimentally $[\mathrm{MPa}]$,

$\mathrm{T}_{0} \ldots$ Room temperature $\left[{ }^{\circ} \mathrm{K}\right]$,

Tm... Melting temperature $\left[{ }^{\circ} \mathrm{K}\right]$,

T... Instantaneous temperature $\left[{ }^{\circ} \mathrm{K}\right]$,

$\dot{\varphi}_{0} \ldots$ Reference strain rate $\left[\mathrm{s}^{-1}\right]$.

For complex analysis each materials constants is necessary compare geometrical parameters specimens of experiments and simulations [8]. To quantification deviations between calculated (simulated) shape and experimental deformed contour is necessary determine average deviations definated as:

$$
\bar{\Delta}=\frac{1}{3}\left[\frac{|\Delta l|}{l_{T}}+\frac{|\Delta d|}{d_{T}}+\frac{|\Delta w|}{w_{T}}\right]
$$

Where:

$1_{\mathrm{T}} . .$. Deformed length $[\mathrm{mm}]$,

$\mathrm{d}_{\mathrm{T}} \ldots$ Deformed diameter $[\mathrm{mm}]$,

$\mathrm{w}_{\mathrm{T}} \ldots$ Deformed buckling $[\mathrm{mm}]$.

Deformed buckling is diameter on $0.21_{0}$ from impact face measured through CCD camera and LUCIA software detachable contour of specimen after loading. Individual deviations $\Delta \mathrm{l}, \Delta \mathrm{d}, \Delta \mathrm{w}$ represent differences between simulated and experimental funds. The average deviations should be minimal - in range between $0-8 \%$. Fig. 5 shows some results of each deviations (length, diameter, buckling and average deviations) for work hardening exponent $\mathrm{n}$.

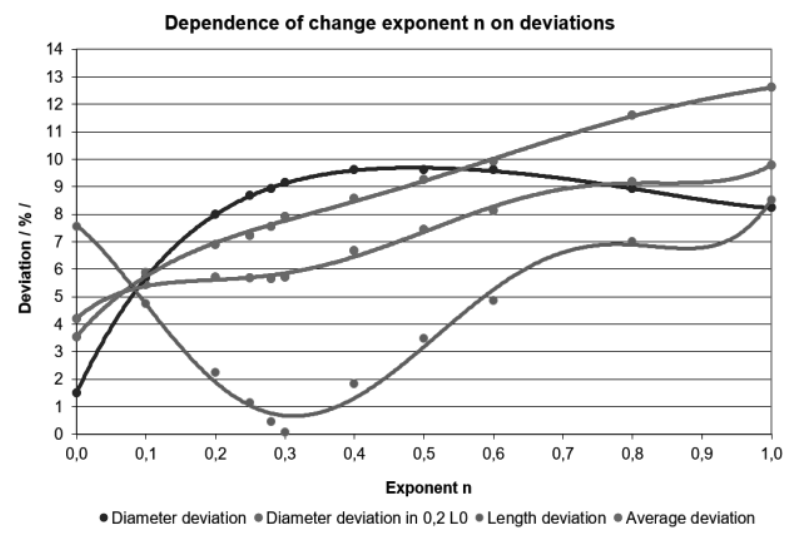

Fig.5 Dependence of change exponent $n$ for individual deviations for the TRIST AL steel 
Fig. 6 shows results of each deviations (length, diameter, buckling and average deviations) for strain rate sensitivity coefficient $\mathrm{C}$.

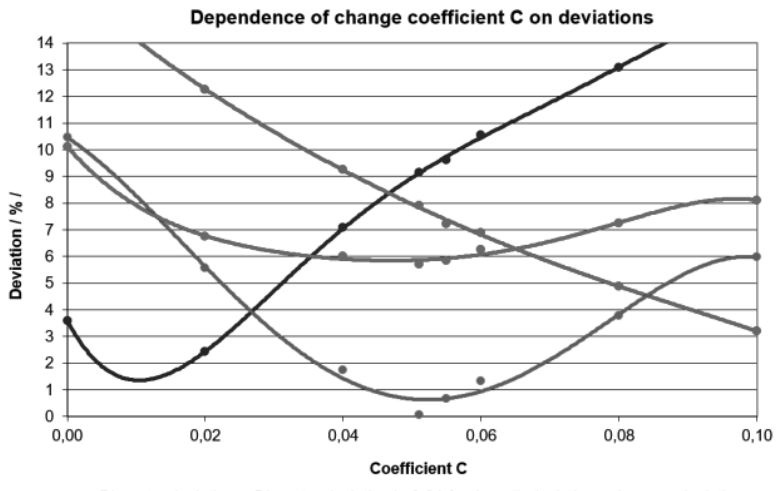

- Diameter deviation •Diameter deviation in $0,2 \mathrm{LO} \bullet$ Length deviation • Average deviation

Fig.6 Dependence of change coefficient $C$ for individual deviations for the TRISTAL steel

\section{Discussion of results}

The practical results of the experiment were compared with the simulation results obtained with the LS DYNA 3D. The Johnson-Cook constitutive equation was used for a mathematical description of the model. An overview of the material constants is shown in Tab. 2.

Tab. 2 Parameters of the Johnson-Cook constitutive equation

\begin{tabular}{|c|c|}
\hline Parameters J-C & TRISTAL steel \\
\hline A [MPa] & 273 \\
\hline B [MPa] & 391 \\
\hline C [-] & 0.051 \\
\hline $\mathrm{n}[-]$ & 0.3 \\
\hline $\mathrm{m}[-]$ & 0.72 \\
\hline
\end{tabular}

The fact that the simulation results and the practically obtained shape are in good agreement between 5- 10\%, is evident from Fig. 7.

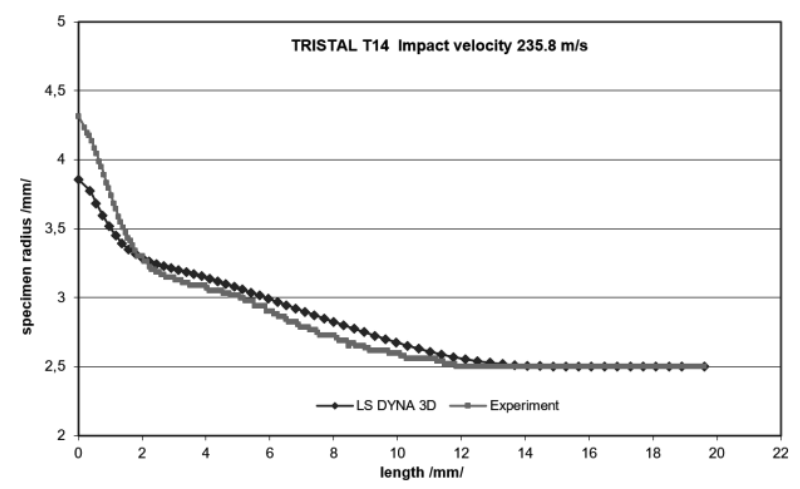

Fig. 7 Comparison of the experiment with the simulation results

Some other results of simulations in the LS DYNA 3D are shown on the Fig. 8, 9 and 10. Fig. 8 shows contours of YZ stress, Fig. 9 shows contours of Pressure, Fig. 10 shows contours of Effective Plastic Strain for TRISTAL steel and impact rate $235,8 \mathrm{~m} / \mathrm{s}$.
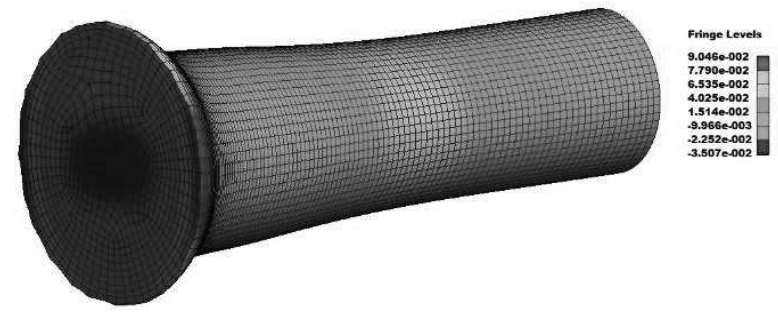

Fig. 8 Contours of $Y Z$ stress
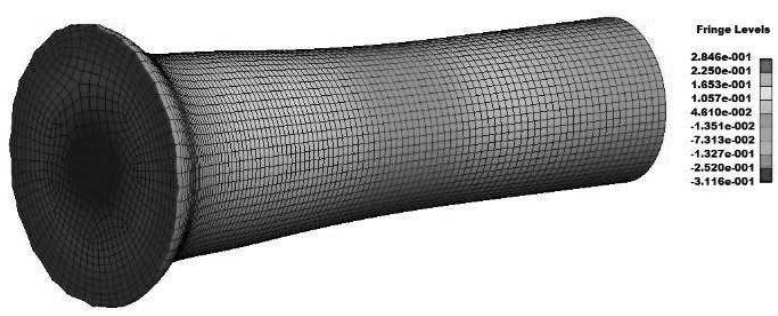

Fig. 9 Contours of Pressure

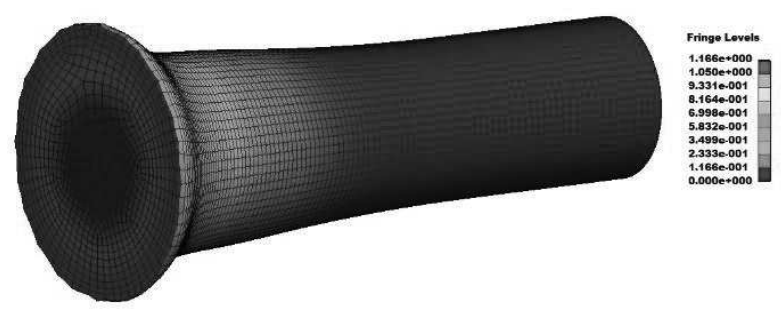

Fig. 10 Contours of Effective Plastic Strain

Based on the comparison of the experiment with the simulation, stress-strain curves depending on temperature and strain rate were proposed. The curves are given for a temperature of $23{ }^{\circ} \mathrm{C}$ and a strain rate between $0.1-1000 \mathrm{~s}^{-1}$. The stress-strain curve by the Johnson-Cook equation for a strain rate of $0.1 \mathrm{~s}^{-1}$ was compared with standard quasi-static compress test and for strain rate $10 \mathrm{~s}^{-1}$ and $30 \mathrm{~s}^{-1}$ with compress test on a cam plastometer. The agreement of curves for TRISTAL steel is evident from Fig. 11.

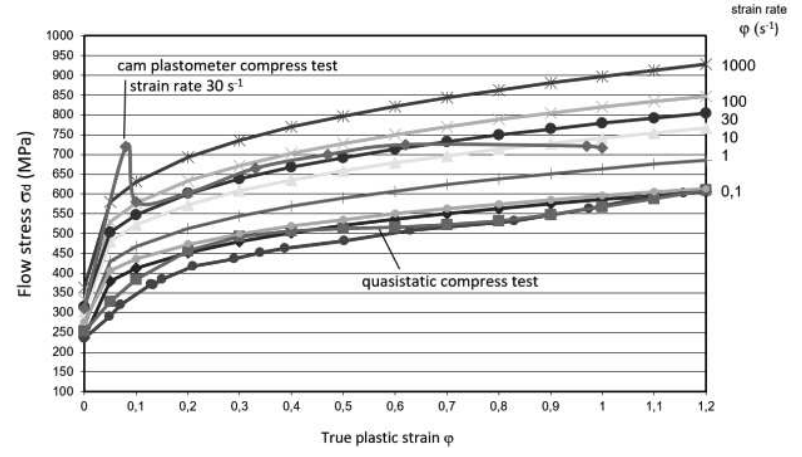

Fig.11 Flow stress curve for TRISTAL steel for temperature of $23^{\circ} \mathrm{C}$. 


\section{Conclusion}

The Johnson-Cook constitutive equation suitably describe the dependence of stress on strain, strain rate and temperature, and they represent well the behaviour of steel. The obtained results show that the Taylor test method is suitable for identifying the parameters of the constitutive equation. The results of the experiment were compared with the results of numerical simulation by the LS DYNA 3D. This comparison points to an agreement between the experimental and the numerical part of the work. The primary task was to compare the results of the constitutive equation from the Taylor test with the results of a conventional quasi-static compression test under given marginal conditions. The good agreement between the stressstrain curves at an initial strain rate of $0.1 \mathrm{~s}^{-1}, 10 \mathrm{~s}^{-1}, 30$ $\mathrm{s}^{-1}$ is evident from Fig. 11.

\section{References}

[1] TAYLOR, G. (1948) The use of flat-ended projectiles for determining dynamic yield stress. I. Theoretical considerations. Proceedings of the Royal Society of London A, pp. 194

[2] ANDERSON, Ch., NICHOLIS, A; CHOCRON, S., RYCKMAN, R. (2006) Shock compression of condensed matter: Proceedings of the Conference of the American Physical Society Topical Group on Shock Compression of Condensed Matter. AIP Conference Proceedings, Volume 845, pp. 1367-1370.
[3] ŘIHÁČEK, J., PETERKOVÁ, E., CÍSAŘOVÁ, M., KUBÍČEK, J. (2020) Comparison of FEM and FVM for the Numerical Simulation of Forging Process. MM Science Journal, vol. 2020, no. 1, p. 3734-3739. ISSN: 18050476.

[4] ŘIHÁČEK, J., PODANÝ, K., FALTÝNEK, F. Prediction of the Stamped Part Thinning Depending on Its Geometry and Blank Material. Manufacturing Technology, 2019, roč. 19, č. 2, pp. 314-320.

[5] BUCHAR, J.-FOREJT, M.-JOPEK, M.KŘIVÁNEK, I. (2000) Evaluation of constitutive relations for high strain rate behaviour using the Taylor Test. Journal Phys. IV France 10, p. $\operatorname{Pr} 9-75$ - $\operatorname{Pr} 9-80$.

[6] MEYER L.W. (1992) Constitutive Equations at High Strain Rates, Shock-W ave and High-StrainRate Phenomena in Materials, Marcel Dekker, Inc., pp. 49-68.

[7] JOHNSON, G.R., COOK, W.H. (1983) A constitutive model and data for metals subjected to large strains, high strain rates and high temperatures. Proceedings of 7 th Symposium on Ballistics (Netherlands, Hague) p 541

[8] VOLKOV, G., BORODIN, E., BRATOV, V. (2017) Numerical simulations of Taylor anvilon-rod impact tests using classical and new approaches. Procedia Structural Integrity, Volume 6, Pages 330-335 